\title{
Fatigue and Physiotherapy in Liver Transplant Recipients
}

\author{
Tuba Ergene ${ }^{1}$ (D), Didem Karadibak² (iD), Kamil Yalcin Polat ${ }^{1}$ (D) \\ ${ }^{1}$ Memorial Atasehir Hospital, Organ Transplantation Centre, Istanbul, Turkey. \\ ${ }^{2}$ Dokuz Eylul University, School of Physical Therapy and Rehabilitation, Department of Cardiopulmonary Physiotherapy, Izmir, Turkey. \\ Correspondence Author: Tuba Ergene \\ E-mail: tuba@ergene.net \\ Received: 22.04.2018 Accepted: 18.06.2018
}

\begin{abstract}
Liver transplantation surgery is a life-saving treatment option for life-threatening end-stage liver diseases and acute liver failure. While the healthrelated quality of life of liver transplant recipients is related to the success of the transplantation procedure; fatigue, malnutrition, loss of muscle mass, decrease in exercise capacity, negative respiratory and metabolic changes as the findings of organ failure are among the causes of functional loss in the posttransplant period. The prevalence of the fatigue, as the frequently experienced symptom in the end-stage liver diseases, varies depending on the specific forms of liver disease and it adversely affects pre and postoperative functional levels of the patients, liver transplantation results and also survival. The severity of the fatigue decreases after the transplantation surgery, but it continues to be seen as the most compelling clinical symptom experienced during the postoperative first year. Current literature data emphasize the necessity of physiotherapy programs and active early mobilization which applied in the early period in the intensive care unit following transplantation surgery and physiotherapy and rehabilitation approaches including strength and endurance training contributes to the functional level in this population. These findings suggest that there is a need for structured physiotherapy programs to increase muscle strength and exercise capacity and prevent fatigue.

Keywords: Exercise training, fatigue, liver transplantation, physiotherapy
\end{abstract}

\section{INTRODUCTION}

Transplantation surgery is considered to be the best liver replacement therapy and a life-saving treatment option for life-threatening end-stage liver failure (1). Although the liver function and survival are improved after transplantation; surgical stress response, physical and psychological problems due to the pathology affect the quality of life negatively $(1,2)$. Many recent studies have focused on the relationship between health-related quality of life and the success rate of transplantation procedure states that transplantation surgery decreases scores representing physical activity parameters of quality of life. The decrease in the level of physical activity is reported to be associated with cachexia, diminishing muscle strength and exercise capacity, loss of range of motion, osteoporosis, malnutrition, pain, arthritis and physical fatigue $(1,3,4)$.

Fatigue has been listed as the most commonly experienced symptom in patients with chronic liver disease (5); it leads to complications, adversely affecting results of liver transplantation as well as survival $(6,7)$. Ney et al. reported that the level of physical activity which is reported by the subjects who have liver failure was low and the major barrier was fatigue (8). Although the severity of fatigue is decreased by transplantation surgery, it remains to be the most challenging clinical symptom experienced within the first postoperative year $(9,10)$. Van den Berg-Emons et al. reported that fatigue is an ongoing symptom in $44 \%$ of recipients in the post-transplant period up to 15 years (11).

The pathogenesis of fatigue is not clear in chronic diseases and liver transplant recipients, however, it is multifactorial in general (5). Since many factors such as age, gender, the level of physical activity, sleep quality, cardiorespiratory fitness, anxiety, and depression are associated with fatigue $(12,13)$; physiotherapy which applied in the early and late postoperative period is extremely important. There is a necessity to introduce patient-specific and structured exercise programs for liver transplant recipients $(14,15)$.

\section{CLINICAL AND RESEARCH IMPACTS}

\section{Liver Transplantation}

Liver transplantation is the procedure in which normal functioning liver tissue from either a living or cadaveric donor is replaced electively in cases with chronic liver diseases or acute fulminant insufficiency (16). Currently, the only proven, definitive treatment modality for the end-stage liver disease is liver transplantation. However, the selection of liver-transplant candidates is extremely important for the success of transplantation (17). Liver failure is characterized 
by the progressive deterioration of hepatic functions in acute or chronic progress. The process itself is critical due to the complications of the disease rather than the liver disease alone; therefore, there is a high mortality risk. In the course of a pretransplant evaluation, recipients should be evaluated thoroughly; thus the identification of high-risk patients is of utmost importance for the success of transplantation surgery. The most commonly used risk scoring methods are the Model of End-Stage Liver Disease (MELD) and Pediatric End-Stage Liver Disease (PELD) scores which is the specific form for children. Model for End-Stage Liver Disease (MELD), The United Kingdom Model for End-Stage Liver Disease (UKELD) (17-19) and Child-Pugh scores are other scoring systems. These systems aim to determine the severity of liver disease and predict the prognosis. The MELD score is known to be more predictive in short-term pretransplant mortality risk prediction (Grade II-1) (18). When MELD and Child-Pugh scoring systems are compared, some studies reported that both are similar for prognostic aspects in many cases and they both have distinctive features for some specific conditions and there is a need for further research to decide which scoring system should be used in which conditions (20).

Perioperative risk assessment includes evaluating comorbidities for liver transplantation such as coronary artery disease, pulmonary hypertension. Patients with hepatic insufficiency have malnutrition, myopathy, and poor physical performance and these secondary outcomes cannot be easily detected with standard cardiorespiratory tests such as 2-dimensional echocardiography and pulmonary function tests $(1,18)$. In resting transthoracic 2-dimensional echocardiography, the normal left ventricular systolic function is defined as an ejection fraction (EF) $>45 \%$ and according to the European Society of Cardiology guidelines, an elevated systolic pulmonary artery pressure (PAP) $>36$ $\mathrm{mmHg}$ is defined as the cutoff value for possible pulmonary hypertension (19).

\section{Fatigue}

The clinical definition of fatigue includes biological, psychosocial and behavioral processes and its' complex interactions along with the prevalence varies depending on the specific form of the liver disease $(21,22)$. Cholestasis causes degenerative central nervous system changes adversely affecting the brain regions which regulates autonomic dysfunction and sleep pattern. These changes lead to many symptoms of fatigue and associated cognitive disorders (2). Besides, autonomic dysfunction contributes to these metabolic changes by limiting the reaction capacity of the muscle to increase in proton/lactate current from the cell and its excretion from tissues (23). Complications in cirrhotic patients such as sarcopenia and hepatic encephalopathy also appear as other causes that lead to fatigue $(24,25)$.

Studies report that chronic liver inflammation is associated with changes in the central nervous system (CNS) emerging as behavioral modifications (26). Liver inflammation also causes changes in brain function. Abnormal central neurotransmission leads to behavioral changes when there isn't any pathological CNS tissue damage present (27). Neurotransmitters associated with central fatigue are corticotropin-releasing hormone $(\mathrm{CRH})$, serotonin and noradrenaline (22). The liver is innervated by vagal nerve afferents that respond to immune mediators such as tumor necrosis factor (TNF $\alpha$ ), interleukin-1 and interleukin-6 (22). The activated vagal nerves affect different regions of the brain potentially leads to subsequent behavioral changes. However, this neural pathway is also thought to play only a minor role in the mechanism of fatigue in chronic liver disease because post-liver transplant patients (in which the liver is deinnervated) often reported a very little change in their perception of fatigue $(22,28)$.

Glial cells and neurons in the brain can produce cytokines leading to behavioral modifications including fatigue. Fatigue is also reported to be associated with alterations of basal ganglion neural activity (22). Stinton and Swain reported that there are still areas where density is even more decreased after a few months of the transplantation. The brain dynamics in those cases where cirrhosis had not recurred indicates that neurological damage may be permanent or recovery is very slow (22).

Despite the pathophysiological mechanisms explaining fatigue exists, there is still not enough data on fatigue's mechanism. Also, it is reported that liver transplantation does not eliminate fatigue. Therefore, further investigation is needed in liver transplant patients to predict fatigue factors and to plan exercise and rehabilitation programs for fatigue management.

\section{Physiotherapy and Rehabilitation}

Even though physiotherapy and rehabilitation programs have benefits in reducing fatigue severity; studies in the literature are limited regarding structured exercise programs.

Studies in liver failure cases are indicated reduced exercise capacity which is measured by maximal oxygen uptake $\left(\mathrm{VO}_{2 \max }\right)(29,30)$ and the inverse correlation between exercise capacity and liver disease severity is remarkable. The decrease in exercise capacity is not only associated with the severity of disease but also considered to be as a predictor of mortality after transplantation. Physical competence, which is one of the most important parameters affecting exercise capacity, is affected by many factors, mainly fatigue, and muscle strength. Studies have emphasized that therapeutic exercises applied to chronic liver failure patients improves physical fitness by improving cardiopulmonary functions (31). These studies especially pointed out a four-week physical training program is needed to improve $\mathrm{VO}_{2 \max }$ by enhancing physical activity level, skeletal muscle volume, and mass (32). Therapeutic exercise approaches are therefore extremely important in managing fatigue in end-stage liver failure $(33,34)$.

Because of a long waiting period is added to the presence of sarcopenia in liver failure cases which are in the transplantation waiting list, rehabilitation programs 
intending to reduce inactivity, improve muscle performance, increase exercise tolerance and prevent postoperative complications are of great importance in this population $(29,35,36)$. Individualized and standardized physical activity programs are acceptable, effective and reliable in patients who are waiting for transplantation. Although however the positive effects of such programs on functional performance and quality of life are known, it is needed for prospective, comprehensive randomized trials to point out promising effects on the post-transplantation process, duration of hospital stay and six-months survival (37).

Studies reported that maximal oxygen consumption of posttransplant patients is $40-60 \%$ lower than expected (38). Beyer et al. had followed liver transplant recipients by supervised exercise program during their first postoperative year. Although they reported the improvement in cardiovascular and neuromuscular capacity, the maximal oxygen consumption, and muscle strength were $10-20 \%$ lower when compared with similar sex and age-matched healthy subjects (39).

Another study observing the relationship between physical fitness deficits and fatigue and health-related quality of life in liver transplant recipients showed that the cardiorespiratory fitness level was significantly impaired in the recipients and the prevalence of obesity was higher than the general population. Consequently, based on the relationship between cardiorespiratory level and fatigue, rehabilitation programs aimed at increasing cardiorespiratory fitness can increase the quality of life by reducing the severity of fatigue after transplant surgery (14).

Current literature data reveals that; loss of muscle mass due to metabolic and nutritional deficits, peripheral neuropathies and pulmonary complications emerging as a result of postural component influences emphasize intensive physiotherapy programs early after transplantation surgery $(37,40)$. The research which evaluated the hemodynamic effects of physiotherapy in intensive care process after liver transplantation suggest that, acute cardiopulmonary responses caused by intensive care physiotherapy in liver recipients are in normal physiological limits (41).

Studies have proved that physical exercise can increase the quality of life in liver transplantation cases. Exercise programs improve the functional capacity based on reduced difficulties encountered in tasks of daily living and by increased patient orientation; as a result, they actively participate in their treatment process. Preoperative patient education, however, may be beneficial in the perioperative and post-transplant recovery period. Limongi et al. followed transplantation candidates for three months which are given patient educations preoperatively and observed improvements in their diaphragm's electrical activity and quality of life. But they also stated that further researches on the benefits of respiratory exercises after liver transplantation surgery are needed (42).
The research findings of Van Ginneken et al. similarly suggest that the effects of endorphins, the encouragement of the patient, positive feedbacks, and social interactions contributed to the post-transplant process; an active lifestyle, improved psychological well-being, and improvement of physical functioning increase the health-related quality of life (43).

There is a need for patient-specific structured and wellplanned physiotherapy interventions to prevent the loss of muscle and bone, to cope with cardiovascular complications and excessive physical fatigue before and after liver transplantation. Specific exercise programs applied to this basis increase muscle strength and endurance, improve aerobic capacity, maximize physical activity level and optimize the health-related quality of life. Secondary beneficial effects of regular exercise in liver recipients are on sleep disorders, depression, and anxiety (15).

Recent studies reported that combined strength training programs and active early mobilization contributes to the postoperative functional performance by increasing activity participation, but it is seen that the number of studies indicating the effect of strength and endurance exercise training in the early period is inadequate $(44,45)$.

A study which investigated physical capacities of liver transplant recipients by the six-minute walk test emphasizes the need for the aerobic exercise to improve physical performance (46). The moderate and high intensity concurrent supervised exercise training program which is administered at the postoperative $6^{\text {th }}$ months has positive effects on $\mathrm{VO}_{2 \text { max }}$ maximal strength, body composition and health-related quality of life in liver transplant recipients (47).

Rehabilitation programs, however, may be effective in reducing fatigue after liver transplantation; taking into account the factors related to fatigue is crucial while setting appropriate programs. Physiotherapy programs aimed at improving exercise capacity can help to reduce posttransplant fatigue and consequently increase the healthrelated quality of life (14). Garcia et al. noticed that aerobic exercises which include 30 minutes of continuous Treadmill workout and 24 sessions in total, make an increase by $19.4 \%$ in walking distances of the post-liver transplant cases (48).

Van den Berg-Emons et al. (11) suggest that fatigue complaints experienced by liver transplant recipients are physical primitively, not psychologically. Van den Berg-Emons et al. also suggested in another study (44) that the severe fatigue sensation of liver transplant recipients was associated with a lower level of daily physical activity. Researchers wanted to pay attention to the negative cycle due to a hypoactive lifestyle and reported that the increase in fatigue perception may lead to more hypoactivity as well as hypoactivity may lead to a decrease in exercise capacity. 


\section{CONCLUSION}

In conclusion; fatigue affects pre - and postoperative functional levels and survival of liver transplantation cases negatively. It is proved in the literature that physiotherapy and rehabilitation approaches including strength and endurance exercise training programs contribute to the functional level of the present patient population; further research is needed $(37,44,45)$.

Aerobic and resistive exercise training programs aimed at improving post-transplant overall health and survival should be essential in post-liver transplantation patients, helping to ensure that physical activity becomes a routine in the treatment plan $(47,49)$.

\section{REFERENCES}

[1] Lucey MR, Terrault N, Ojo L, Hay JE, Neuberger J, Blumberg $E$, Teperman LW. Long-term management of the successful adult liver transplant: 2012 practice guideline by the American Association for the study of liver diseases and the American Society of Transplantation. Liver Transpl 2013; 19(1): 3-26.

[2] Lin XH, Teng S, Wang L, Zhang J, Shang YB, Liu HX, Zang YJ. Fatigue and its associated factors in liver transplant recipients in Beijing: a cross-sectional study. BMJ Open 2017; 7(2): e011840.

[3] Dove LM, Brown RS. Liver transplantation in adults: Patient selection and pretransplantation evaluation. UpToDate, Waltham, M.A. 2017; (Accessed on December 4, 2014.).

[4] Toshikuni N, Arisawa N \& Tsutsumi M. Nutrition and exercise in the management of liver cirrhosis. WJG 2014; 20(23): 7286.

[5] Swain, MG. Fatigue in liver disease: pathophysiology and clinical management. Can J Gastroenterol Hepatol 2006; 20(3): 181-188.

[6] Kalaitzakis $E$, Josefsson A, Castedal $M$, Henfridsson $P$, Bengtsson M, Hugosson I, Andersson B, Björnsson E. Factors related to fatigue in patients with cirrhosis before and after liver transplantation. Clin Gastroenterol Hepatol 2012; 10(2): 174-181.

[7] Magalhães CBA, Nogueira IC, Marinho LS, Daher EF, Garcia JHP, Viana CF, de Bruin PFC, Pereira ED. Exercise capacity impairment can predict postoperative pulmonary complications after liver transplantation. Respiration 2017; 94(3): 272-278.

[8] Ney M, Gramlich L, Mathiesen V, Bailey R J, Haykowsky M, Ma M, Abraldes JG, Tandon P. Patient-perceived barriers to lifestyle interventions in cirrhosis. Saudi J Gastroenterol: official journal of the Saudi Gastroenterology Association 2017; 23.2: 97.

[9] Gross CR, Malinchoc M, Kim WR, Evans RW, Wiesner RH, Petz JL, Crippin JS, Klintmalm GB, Levy MF, Ricci P, Therneau TM, Dickson ER. Quality of life before and after liver transplantation for cholestatic liver disease. Hepatology 1999; 29(2): 356-364.

[10] Belle SH, Porayko MK, Hoofnagle JH, Lake JR, Zatterman RK. Changes in quality of life after liver transplantation among adults. National Institute of Diabetes and Digestive and Kidney Diseases (NIDDK) Liver Transplantation Database (LTD). Liver Transpl Surg 1997; 3(2): 93-104.

[11] Van den Berg-Emons R, van Ginneken B, Wijffels M, Tilanus H, Metselaar $\mathrm{H}$, Stam $\mathrm{H}$, Kazemier $\mathrm{G}$. Fatigue is a major problem after liver transplantation. Liver Transpl 2006(a); 12(6):928933.
[12] Hong K, Kim H, Lee JM, Lee KW, Yi NJ, Lee HW, Choi YR, Suh SW, Hong SK, Yoon KC, Kim HS, Suh KS. Fatigue and related factors after liver transplantation. Korean J Hepatobiliary Pancreat Surg 2015; 19(4): 149-153.

[13] Aadahl M, Hansen BA, Kirkegaard P, Groenvold M. Fatigue and physical function after orthotopic liver transplantation. Liver Transpl 2002; 8(3): 251-259.

[14] Van Ginneken BTJ, van den Berg-Emons RJ, Kazemier G, Metselaar HJ, Tilanus HW, Stam HJ. Physical fitness, fatigue, and quality of life after liver transplantation. Eur J Appl Physiol 2007; 100(3): 345-353.

[15] Meric Senduran and Ufuk Yurdalan. Physiotherapy in Liver Transplantation. Prof. Hesham Abdeldayem (Ed.). Liver Transplantation-Technical Issues and Complications. InTech. 2012.p.445-54. Abdeldayem, H., \& Allam, N. (Eds.). (2012). Liver Transplantation: Technical Issues and Complications. BoD-Books on Demand.

[16] Kasapoğlu B, Yalçın KS, Türkay C. Canlı donörden karaciğer transplantasyonu. Güncel Gastroenteroloji 2010; 14(2): 96102.

[17] Martin P, DiMartini A, Feng S, Brown R, Fallon M. Evaluation for liver transplantation in adults: 2013 practice guideline by the American Association for the Study of Liver Diseases and the American Society of Transplantation. Hepatology 2014; 59(3): 1144-1165.

[18] Burra P, Burroughs A, Graziadei I, Pirenne J, Valdecasas JC, Muiesan $P$, Samuel D, Forns X. EASL clinical practice guidelines: liver transplantation. J Hepatol 2016; 64(2): 433-485.

[19] Ow MMG, Erasmus P, Minto G, Struthers R, Joseph M, Smith A, Warshow UM, Cramp ME, Cross TJ. Impaired functional capacity in potential liver transplant candidates predicts shortterm mortality before transplantation. Liver Transpl 2014; 20(9): 1081-1088.

[20] Peng Y, Qi X, Guo X. Child-Pugh Versus MELD Score for the assessment of prognosis in liver cirrhosis: a systematic review and meta-analysis of observational studies. Medicine 2016; 95(8): e2877.

[21] D'Mello C, Swain MG. Liver-brain interactions in inflammatory liver diseases: implications for fatigue and mood disorders. Brain Behav Immun 2014; 35: 9-20.

[22] Stinton L, Swain MG. Fatigue in cirrhosis: is transplant the answer? Clin Gastroenterol Hepatol 2012; 10(2): 103-105.

[23] Griffiths L, Jones DE. Pathogenesis of primary biliary cirrhosis and its fatigue. Dig Dis 2014; 32(5): 615-625.

[24] Dasarathy S, Merli M. Sarcopenia from mechanism to diagnosis and treatment in liver disease. J Hepatol 2016; 65(6): 12321244.

[25] Kalaitzakis E, Josefsson A, Castedal M, Henfridsson P, Bengtsson $M$, Andersson B, Björnsson E. Hepatic encephalopathy is related to anemia and fat-free mass depletion in liver transplant candidates with cirrhosis. Scand J Gastroenterol 2013; 48(5): 577-584.

[26] D'Mello C, Swain MG. Liver-brain inflammation axis. Am J Physiol Gastrointest Liver Physiol 2011; 301(5): G749-G761.

[27] Pollak Y, Ovadia H, Orion E, Weidenfeld J, Yirmiya R. The EAEassociated behavioral syndrome: I. Temporal correlation with inflammatory mediators. J Neuroimmunol 2003; 137: 94-99.

[28] McDonald C, Newton J, Lai HM, Baker SN, Jones DE. Central nervous system dysfunction in primary biliary cirrhosis and its relationship to symptoms. J Hepatology 2010; 53(6): 10951100. 
[29] Lemyze M, Dharancy S, Nevière R, Wallaert B. Cardiopulmonary response to exercise in patients with liver cirrhosis and impaired pulmonary gas exchange. Respir Med 2011; 105(10): 1550-1556.

[30] Terziyski K, Andonov V, Marinov B, Kostianev S. Exercise performance and ventilatory efficiency in patients with mild and moderate liver cirrhosis. Clin Exp Pharmacol Physiol 2008; 35(2): 135-140.

[31] Koya S, Kawaguchi T, Hashida R, Goto E, Matsuse H, Saito H, Hirota K, Taira R, Matsushita Y, Imanaga M, Nagamatsu A, Shirono $\mathrm{T}$, Shimose $\mathrm{S}$, Iwamoto $\mathrm{H}$, Niizeki T, Kuromatsu R, Miura $H$, Shiba N, Torimura T. Effects of in-hospital exercise on liver function, physical ability, and muscle mass during treatment of hepatoma in patients with chronic liver disease. Hepatol Res 2017; 47(3): E22-E34.

[32] Alameri HF, Sanai FM, Al Dukhayil M, Azzam NA, Al-Swat KA, Hersi AS, Abdo AA. Six minute walk test to assess functional capacity in chronic liver disease patients. World J Gastroenterol 2007; 13(29): 3996-4001.

[33] Golse N, Bucur PO, Ciacio O, Pittau G, Sa Cunha A, Adam R, Castaing D, Antonini T, Coilly A, Samuel D, Cherqui D, Vibert E. A new definition of sarcopenia in patients with cirrhosis undergoing liver transplantation. Liver Transpl 2017; 23(2): 143-154.

[34] Lemyze $M$, Dharancy S, Wallaert B. Response to exercise in patients with liver cirrhosis: implications for liver transplantation. Dig Liver Dis 2013; 45(5): 362-366.

[35] Kaido T, Tamai $Y$, Hamaguchi $Y$, Okumura $S$, Kobayashi $A$, Shirai H, Yagi S, Kamo N, Hammad A, Inagaki N, Uemoto S. Effects of pretransplant sarcopenia and sequential changes in sarcopenic parameters after living donor liver transplantation. Nutrition 2017; 33: 195-198.

[36] Bernal W, Martin-Mateos R, Lipcsey M, Tallis C, Woodsford K, McPhail MJ, Willars C, Auzinger G, Sizer E, Heneghan M, Cottam S, Heaton N, Wendon J. Aerobic capacity during cardiopulmonary exercise testing and survival with and without liver transplantation for patients with chronic liver disease. Liver Transpl 2014; 20(1): 54-62.

[37] Pieber K, Crevenna R, Nuhr MJ, Quittan M, Peck-Radosavljevic M, Fialka-Moser V, Wiesinger GF. Aerobic capacity, muscle strength and health-related quality of life before and after orthotopic liver transplantation: preliminary data of an Austrian transplantation centre. J Rehabil Med 2006; 38(5): 322-328.
[38] Stephenson AL, Yoshida EM, Abboud RT, Fradet G, Levy RD. Impaired exercise performance after successful liver transplantation. Transplantation 2001; 72(6): 1161-1164.

[39] Beyer N, Aadahl M, Strange B, Kirkegaard,P, Hansen BA, Mohr T, Kjær M. Improved physical performance after orthotopic liver transplantation. Liver Transpl Surg 1999; 5(4): 301-309.

[40] Feltracco P, Barbieri S, Galligioni H, Michieletto E, Carollo C, Ori C. Intensive care management of liver transplanted patients. World J Hepatol 2011; 3(3): 61-71.

[41] Senduran M, Yurdalan SU, Karadibak D, Gunerli A. Haemodynamic effects of physiotherapy programme in intensive care unit after liver transplantation. Disabil Rehabil 2010; 32(17): 1461-1466.

[42] Limongi V, Dos Santos DC, de Oliveira da Silva AM, Boin Ide F, Stucchi RS. Exercise manual for liver disease patients. World J Transplant 2016; 6(2): 429-436.

[43] van Ginneken BT, van den Berg-Emons HJ, Metselaar HJ, Tilanus HW, Kazemier G, Stam HJ. Effects of a rehabilitation programme on daily functioning, participation, health-related quality of life, anxiety and depression in liver transplant recipients. Disabil Rehabil 2010; 32(25): 2107-2112.

[44] van den Berg-Emons R, Kazemier G, van Ginneken B, Nieuwenhuijsen C, Tilanus H, Stam H. Fatigue, level of everyday physical activity and quality of life after liver transplantation. J Rehabil Med 2006; 38(2): 124-129.

[45] Jones JC, Coombes JS, Macdonald GA. Exercise capacity and muscle strength in patients with cirrhosis. Liver Transpl 2012; 18(2): 146-151.

[46] Foroncewicz B, Mucha K, Szparaga B, Raczyńska J, Ciszek M, Pilecki T, Krawczyk M, Pączek L. Rehabilitation and 6-minute walk test after liver transplantation. Transplant Proc 2011; 43(8): 3021-3024.

[47] Moya-Nájera D, Moya-Herraiz Á, Compte-Torrero L, Hervás D, Borreani S, Calatayud J, Berenguer M, Colado JC. Combined resistance and endurance training at a moderate-to-high intensity improves physical condition and quality of life in liver transplant patients. Liver Transpl 2017; 23(10): 1273-1281.

[48] Garcia AM, Veneroso CE, Soares DD, Lima AS, Correia MI. Effect of a physical exercise program on the functional capacity of liver transplant patients. Transplant Proc 2014; 46(6): 18071808.

[49] Basha MA, Mowafy ZE, Morsy EA. Sarcopenic obesity and dyslipidemia response to selective exercise program after liver transplantation. Egyptian Journal of Medical Human Genetics 2015; 16(3): 263-268

How to cite this article: Ergene T., Karadibak D., Polat K. Y. Fatigue and Physiotherapy in Liver Transplant Recipients. Clin Exp Health Sci 2019; 9: 278-282. DOI: 10.33808/clinexphealthsci.599730 